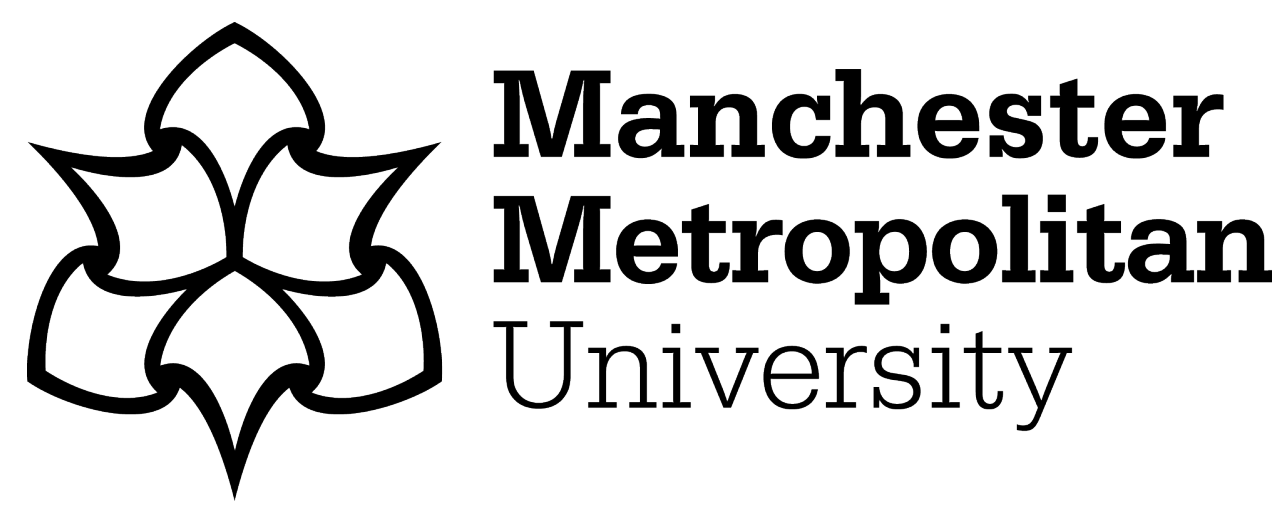

Vassilakaki, E and Johnson, F (2015) The use of grounded theory in identifying the user experience during search. Library and Information Science Research, 37 (1). pp. 77-87. ISSN 0740-8188

Downloaded from: https://e-space.mmu.ac.uk/616969/

Version: Accepted Version

Publisher: Elsevier

DOI: https://doi.org/10.1016/j.lisr.2014.06.006

Usage rights: Creative Commons: Attribution-Noncommercial-No Derivative Works 4.0

Please cite the published version 
This is the peer reviewed version of the following article: Vassilakaki, E. Johnson, F, The use of grounded theory in identifying the user experience in search. Library and Information Science Library and Information Science Research, 37(1),2015 pp77-87 doi:10.1016/j.lisr.2014.06.006, which has been published in final form at http://www.sciencedirect.com/science/article/pii/S0740818815000079.

\title{
The use of grounded theory in identifying the user experience in search.
}

\author{
E Vassilakaki, Johnson, F \\ Manchester Metropolitan University
}

\begin{abstract}
Grounded theory offers a useful method for gaining an understanding of the context of the user experience when searching on an experimental multilingual image retrieval system. Observational, cognitive and affective data were collected while users searched for images in a multilingual environment. Straussian grounded theory was used to identify the elements of the dynamic process of information searching behaviour. The stages in which the data were coded are outlined to show how users' thoughts and actions were integrated in the analysis and to present and visualise the emerging concepts as representative of the context of the user experience.
\end{abstract}

\section{Introduction}

Multilingual information retrieval (MLIR) systems are intended to accept queries in a single language and through translation retrieve objects indexed in other languages (Chen \& Gey, 2004; Jorna \& Davies, 2001). .

A variety of different models have been developed in the context of studying user-oriented and cognitive information retrieval research (Jarvelin \& Ingwersen, 2012). These include generic models which are trying to model a large domain (Ingwersen \& Wormell, 1988; Wilson, 1999)); relevance models which focus either on user-oriented topical relevance, or a more dynamic, multidimensional and multigraded relevance (Borlund, 2003; Cosijn \& Ingwersen 2000; ,Saracevic, 1996; Wang \& Soergel, 1998)and); process models exploring users' behaviour in an online, interactive, typically in Boolean-based professional or work environment (Bates, 1979; Fidel \& Soergel, 1983); models which focus on cognitive structures and actors (Belkin, 1978; Belkin, Oddy, \& Brooks, 1982; Ellis, 1989; Marchionini, 1995); and task-based models (Ingwersen \& Jarvelin, 2005; Vakkari, 2001a, 2001b),). All have the common goal of providing insights into users' information seeking behaviour, and in many occasions these complemented one another (Jarvelin \& Ingwersen, 2012).

As a process model, users' information seeking behaviour (ISB) has been studied both as linear and non-linear. In particular, Foster's (2004) model of ISB depicts a non-linear process with users' characteristics (such as cognition) influencing the core processes of opening, orientation, and consolidation. Furthermore emotions such as motivation, feelings of uncertainty, and confidence have been shown to affect the information seeking process (Choo \& Marton, 2003; Mackenzie, 2003;). While seeking for information is known to be a process which is subject to contextual influences, the process can be explored from the ground up and specifically to gain a better 
understanding of search behaviour when interacting with an information retrieval system. Drawing on the terminology from grounded theory (GT), a qualitative method of data analysis, information searching may be studied as a phenomenon in which the dynamic and fluid process of information searching can be identified from user actions and their thoughts and expressions. Towards this end, the present study employs GT to analyse data collected on users' searching behaviour, with an emphasis on the coding and analysis approach adopted. The inductive approach of GT coupled with its procedural analysis enables the study of what is essentially the flow found in information searching behaviour, and specifically the approach enables:

- the analysis of users' actions and interactions, the consequences, and their thoughts and expressions while interacting with a MLIR system; , as well as

- the identification of the factors which seem to influence and inform users' search behaviour.

\section{Problem statement}

Searching for information is a dynamic process influenced by a variety of factors. Grounded theory has been adopted by a number of studies to shed light on the factors influencing users' searching behaviour but few such studies address the dynamic nature of information searching. Moreover, previous studies have tended to focus on describing models of information seeking in general rather than on the detailed steps users undertake to search for information. The present study adopts procedural analysis, that is a sequence of stages which change over time, to provide detailed analysis of users' image searching behaviour in a multilingual environment. Data are broken down, coded, analysed and reassembled to reflect the procedural nature of users' behaviour while searching for information.

Thus, in this study GT is used to analyse user interaction in depth, with the collection of as much data as possible on users' actions and contextual information. The three coding steps of Straussian GT (open, axial and selective) are applied to explore users' behaviour and to identify the concepts and relationships in order to build what is termed the substantive theory. The categories and concepts which emerge and the substantive theory are presented only as an outcome of the analysis approach - the approach itself is the main focus of the present study. In depth discussion of the user experience when described and modelled by the influencing factors can be found in Vassilakaki, Johnson and Hartley (2012).

Identifying users' information searching behaviour and search patterns and especially users' own interpretations of the system in use is essential for developing information retrieval systems that meet users' information needs. The additional element of thinking about languages and searching across languages in multilingual systems adds cognitive challenges to users and highlights the importance of knowing more about user ISB. The present research contributes in providing a way of analysing procedural data to gain better understanding of the processes in which users are involved during search. In addition, it provides another way of exploring, analysing, and modelling users' searching behaviour, and offers specific guidelines for identifying the processes discernible from the data. Finally, it contributes a valuable insight into users' thought processes and explanations during searches and thus informs the design, development,t and evaluation of effective multilingual information retrieval systems.

\section{Literature review}


Users' information seeking behaviour has been investigated both as static and linear (Kuhlthau, 1993; Wilson, 1997) and as a dynamic, interactive and non-linear process subject to a range of influences (Foster, 2004). In these studies a variety of methods, either only quantitative, or only qualitative and sometimes a mixture of both have been employed (McKechnie, Baker, Greenwood, \& Julien, 2002; Vakkari, 2008). Qualitative research encompasses a variety of approaches and methodologies (Flick 2004; González-Teruel \& Abad-García, 2012) and GT is a wholly qualitative method of data analysis (Urquhart, Lehmann, \& Myers,, 2009), originating from Glaser and Strauss (1967). GT aims to systematically derive theories of human behaviour from empirical data. While the philosophy of GT as a research method can raise debate, it is based on a straightforward notion that the researcher can set aside theoretical ideas on the phenomenon under investigation to ensure an inductive approach is taken in identifying characteristic concepts in the qualitative data.

GT has gained momentum gradually but steadily and for some has been considered one of the main methodologies for exploring users' information seeking behaviour in various contexts (GonzálezTeruel \& Abad-García, 2012). For example, GT has been used to provide a model of information seeking behaviour derived from a review of Jewish studies scholars (Bronstein, 2007); model the information behaviour of on-duty critical care nurses (McKnight, 2007); and develop an interaction value model (Musoke, 2007). . Winkelman, Leonard and Rossos (2005) use GT to analyse factors regarding the perceived usefulness of online medical records by patients. Xie (2009) analysed the theoretical framework which influenced the development of health information needs. Correia and Wilson (2001) presented the core factors emerging from analysis as categories which influenced users' environmental scanning activity, and Pace (2004) explored the development of a theory to describe users' experiences on the Web.

Both Glaserian GT (Glaser \& Strauss, 1967) and Straussian GT (Strauss \& Corbin, 1998) have been employed in studies of information behaviour. Glaser divides the coding process into two procedures: substantive and theoretical coding. Substantive coding consists of two phases, open and selective coding, whereas theoretical coding refers to the relating of substantive codes to each other to formulate hypothesis and theory (Walker \& Myrick, 2006). Thus the coding in Glaserian GT consists of the identification of categories and subcategories and the relations between them. In Straussian GT, there are two types of analysis for concepts and for coding in process. The difference between the two is that instead of looking for properties and their relations during the analysis for concepts, coding in process identifies and traces actions/interactions over time. This process can be defined as a series of evolving sequences of actions and interactions over time and space, changing or staying the same depending on the situation or the context. The study of the actions and interactions is a study of a process because of its evolving nature and the variety of forms relating to a purpose (Strauss \& Corbin, 1998). Furthermore in Straussian GT, the integration of the users' thoughts and expressions (conditions) with process (actions and interactions and consequences) leads to the emergence of research questions that explain the phenomenon studied. These questions when applied to data enable the emergence of factors and the identification of their relationships in the emerging theory (Strauss \& Corbin, 1998).

Previous studies that have adopted GT to explore information seeking behaviour have adopted a static analysis of the data obtained. In particular, these studies did not treat, or model, the process of searching as a sequence of stages changing over time but more like a situation which stays the same regardless of time. Concepts or categories and sub-concepts or subcategories, as well as their relationships, may be identified from a static coding, although information seeking is clearly a process - a sequence of stages which evolve over time (Jarvelin \& Ingwersen, 2012; Strauss \& Corbin, 1998). The adoption of procedural analysis in the present study seeks to identify the 
concepts when coding the mental thoughts that take place in the physical process of an actual search.

\section{Procedures}

The Strauss and Corbin (1998) guidelines were adopted to analyse the data for the identification of conceptual categories and to enable procedural analysis. Specifically, three approaches to analysis were adopted: open coding to allow for the emergence of the core concepts and their properties; axial coding to allow for the identification of the process in the data and consequently users actions and interactions, conditions, and consequences that were core to the process; and finally, selective coding to allow for the integration of the data and discovery and refinement of the substantive theory. In all three approaches, the process of constant comparison was used in an attempt to compare not only users' actions and interactions and consequences of these actions with a view to finding similarities or differences, but also users' thoughts and explanations of these actions. Constant comparison enabled a better insight into both users' actions and most importantly users' thoughts.

\subsection{The system}

This study used FlickLing, a basic cross-language search front-end to the well-known web application Flickr, developed for user behaviour experiments in the interactive CLEF track (iClef track) of the Cross-Language Evaluation Forum (CLEF; Clough et al., 2008). FlickLing consists of two modes: the monolingual and the multilingual mode (Peinado, Lopez-Osterno, \& Gonzalo, 2009). In the monolingual mode, users can search and retrieve images only in one language, that is, the search term(s) are matched only against index terms in that same language. The multilingual mode provides a translation mechanism which enables images to be retrieved regardless of the languages used in its header and tags. Users of FlickLing can choose in which of the six supported languages they want to express the query. The system automatically provides the translations in the chosen languages, retrieves the images from the collection and presents the results to the user. Furthermore each time a user runs a query either in monolingual or multilingual mode, FlickLing presents to the user a list with suggested terms based on the tags found on the images retrieved, enabling users to include further keywords. Finally, FlickLing offers two choices to users: clicking the "give up" button or taking a hint on how to successfully retrieve the image sought in the given task.

\subsection{Task}

Users were required to search for three pre-selected images. The users did not know in which of the six languages (English, German, Dutch, Spanish, French, and Italian) the images were described thus requiring them to use both mono-lingual and multilingual modes. The sought images were described in Dutch, German and Spanish and were chosen on the basis that they had in the image some visual clue such as a landmark or written text, thus indicating the need to search in the associated language. The Dutch image was chosen because the windmills were thought to be representative of The Netherlands, the German image had text in German ("polizei") revealing its language. The Spanish image was chosen because it was representative of the carnival in Mexico. All selected images had both a heading and at least three tags, thus providing many access points.

\subsection{User sampling}

The sampling strategy used theoretical sampling as defined in Straussian GT (Strauss and Corbin, 
1998). The sample was not pre-defined but rather formulated during the data collection process and there was no control over gender, age, or knowledge of foreign languages. Users from the undergraduate and postgraduate populations of the Department of Languages, Information \& Communications at Manchester Metropolitan University (MMU) were invited before and while conducting the study to participate voluntarily. The number of users had to be sufficient to collect the necessary amount and types of data to reach the desired theoretical saturation. In total, 24 participants, referred to in this study as the users, were recruited. The number of users was considered enough for the purposes of this small-scale study because the amount and types of data collected were thought sufficient for reaching a desired degree of theoretical saturation. Parallel analysis of the data collected assisted in deciding that a theoretical saturation was reached, especially for the main conceptual categories of users' searching experiences in multilingual environments.

\subsection{Data collection tools}

In GT, the constant comparison method is employed for generating theory where both qualitative and quantitative methods can be considered tools for collecting necessary data, although GT is in practice mainly associated with qualitative research. GT provided the freedom to use all appropriate methods for collecting different types of necessary data, since methods are regarded as tools for data collection and there were no limitations regarding the number and type of methods employed. 
There were three phases to data collection (Table 1). A pre-study questionnaire was used to collect demographic information (age, gender, and education) as well as native language and users' level of comprehension for each of the six languages offered by FlickLing. In addition users were asked to state their experience in searching for images on the web and in searching across languages for images. In a second questionnaire, all users were asked to respond to a series of statements concerning their trust and confidence in searching on the web. Finally in a third, post-task, questionnaire, users were asked to indicate their trust in FlickLing and confidence in their searching skills in FlickLing (Appendix A). A form was created to assist in the collection of data during observation of the users' behaviour. This form was categorized according to the areas that were to be investigated. Each category had a set of predefined questions and remarks that the facilitator completed according to the user's behaviour, and space was provided to record additional comments for the questions to be asked to users during individual interviews. A set of three forms, one for each image, and one for each user was used. Retrospective thinking aloud was also used by videorecording each user's search session and then playing the session back and asking users to describe their actions and thoughts at that time. Their comments were recorded. The last part of the study consisted of a brief interview with each user immediately after the completion of the retrospective thinking aloud. The interview lasted no more than 10 minutes. The questions varied according to users' answers to the questionnaires, the notes taken during observation, and users' explanations in retrospective thinking aloud. 
Table 1. Different types of data assigned to phases

\begin{tabular}{|c|c|c|c|c|}
\hline $1^{\text {st }}$ phase & \multicolumn{3}{|c|}{$2^{\text {nd }}$ phase } & $3^{\text {rd }}$ phase \\
\hline \multirow{2}{*}{$\begin{array}{c}\text { Before engaging with } \\
\text { the task }\end{array}$} & \multicolumn{3}{|c|}{ Searching the three images } & After engaging with \\
\hline & $1^{\text {st }}$ image & $2^{\text {nd }}$ image & $3^{\text {rd }}$ image & \\
\hline $\begin{array}{l}\text { User sample ( } 1^{\text {st }} \\
\text { questionnaire) } \\
\text { Trust confidence } \\
\text { comments }\left(2^{\text {nd }}\right. \\
\text { questionnaire, } \\
\text { interviews) } \\
\text { Users' expressions } \\
\text { before interacting } \\
\text { with the interface } \\
\text { (RTA) }\end{array}$ & $\begin{array}{l}\text { Actions and } \\
\text { interactions } \\
\text { Conditions } \\
\text { Consequences } \\
\text { (videos, RTA) }\end{array}$ & $\begin{array}{l}\text { Actions and } \\
\text { interactions } \\
\text { Conditions } \\
\text { Consequences } \\
\text { (videos, RTA) }\end{array}$ & $\begin{array}{l}\text { Actions and } \\
\text { interactions } \\
\text { Conditions } \\
\text { Consequences } \\
\text { (videos, RTA) }\end{array}$ & $\begin{array}{l}\text { Trust and confidence } \\
\left(2^{\text {nd }} \& 3^{\text {rd }} \text { questionnaire }\right. \\
\& \text { interviews })\end{array}$ \\
\hline
\end{tabular}

Data collection was carried out in March and May 2009. On arrival, users were asked to complete the first two questionnaires. Then, the facilitator read the instructions to the user and the user was encouraged to register and login to FlickLing. On completion of the task, the third questionnaire was given to the user to fill in. Then the recording was played back to the user, asking them to describe their actions and especially thoughts. A digital voice recorder was used to capture the user's comments and explanations. Finally, the semi-structured interview was carried out.

\section{Analysis}

\subsection{Open coding}

This study collected a variety of data in the different phases.. These data were broken down into discrete parts and were closely compared for similarities or differences. The first questionnaire was analysed in an attempt to bring out users' knowledge of languages and previous experience in searching for images across languages. The second and third questionnaires were analysed to find the mean scores of users' trust and confidence in searching and language skills, both in general and in FlickLing. This analysis was purely to obtain a better understanding of the users' characteristics as a context in which to obtain an understanding of the data gathered throughout the search tasks.

The main coding took place on the recordings of users' actions during the search tasks. Each of the 24 recordings was played back and user's actions were represented in the form of a diagram and in sequence. Actions such as search terms used, various clicks on the interface's features (tags, suggestions, modes, give up, hints), the number of results retrieved, and the number of pages scanned were represented in a graphical way for all three images. Time of completion for every image was also recorded. In this way, it was possible to represent users' actions/interactions and the consequences of their actions (Table 2.).

Table 2. Video coding

\begin{tabular}{|c|}
\hline User G1/01 \\
\hline $1^{\text {st }}$ image \\
\hline monolingual mode \\
\hline
\end{tabular}




\begin{tabular}{|c|}
\hline$\ldots$ \\
\hline$[$ typed] windmill holland \\
\hline$[$ clicked] search \\
\hline 500 retrieved results \\
\hline scrolled down \\
\hline$\ldots$ \\
\hline
\end{tabular}

The 24 diagrams, one for each user for all three images, were then compared in an attempt to find similarities and differences among users' actions and interactions. In particular, users' choice of specific mode to start the search, choice of search terms, use of hints, and number of pages scanned and stopping a search enabled the constant comparison of users' actions and interactions during the different stages of search for the three images. These actions and interactions were compared separately for the first, second, and third image since each user searched all three. This further enabled the emergence of codes shedding light on the diversity of the actions and interactions as well as the reasons for performing these actions.

The transcripts created from retrospective thinking aloud were read through several times to form an idea of what sort of data were in the transcripts. While going through the transcripts, users' expressions that seemed important or had some significance to what they was doing and how they explaining their actions were underlined. These expressions were coded after a constant comparison of users' narrations in an attempt to identify the different concepts. Tables were created to group these expressions under each user and for each image separately. Users' expressions were copied in these tables instead of taking notes to avoid any misinterpretations or bias. These key areas formulated the concepts. A further comparison of users' expressions for each concept separately resulted in the emergence of codes and sub-codes.

The concepts and their codes and sub-codes which emerged after a constant comparison of users' expressions enabled the identification of the prominent factors in the phenomenon of users' searching experiences in multilingual environments. The first step in the coding in process resulted in the identification of 27 concepts (Table 3.).

Table 3. Concepts

\begin{tabular}{|l|l|l|l|}
\hline Concepts & 15 & Giving up \\
\hline 1 & Users' feelings & 16 & Suggestions usage \\
\hline 2 & Google comments & 17 & System automatically retrieving translations \\
\hline 3 & Headings and tags usage & 18 & System playing around \\
\hline 4 & Hints usage & 19 & Thinking about languages \\
\hline 5 & “I write in language" feature usage & 20 & Thinking of doing something wrong \\
\hline 6 & $\begin{array}{l}\text { Importance of knowing the language of the } \\
\text { image }\end{array}$ & 21 & Usage of language as a search term \\
\hline 7 & "Language buttons" feature usage & 22 & Reasons for clicking the "give up" button the first time \\
\hline 8 & Language skills & 23 & Users' comments regarding the way they searched in \\
\hline 9 & Linking system & 24 & Users' confidence \\
\hline 10 & Modes interpretation &
\end{tabular}




\begin{tabular}{|l|l|l|l|}
\hline 11 & Modes usage & 25 & Users' expressed reasons for ceasing a search \\
\hline 12 & Overall impression of translation mechanism & 26 & $\begin{array}{l}\text { Users' expressions when first confronted with the given } \\
\text { images }\end{array}$ \\
\hline 13 & Paying attention to translations & 27 & Users' trust \\
\hline 14 & Problems encountered before finding the image & & \\
\hline
\end{tabular}

The process by which the concepts emerged from the data is illustrated with the analysis of one of the concepts "paying attention to translations" (highlighted in Table 3.). Initially, users' comments referring to this concept were grouped and for each image separately. The comments in Table 4 are labelled with code,s for example, expectation, amount of retrieved results to summarise the expressions used by the user when explaining in the concept under identification. It can be seen in the table that for each concept (e.g., paying attention to translation) there were further sub-codes. For example, clicked on translations or retyped the translations. Furthermore the users' coded justifications were further grouped for all users and for all images (Column 4, Table 4). This was done to move towards towards abstracting the data and generating the substantive theory.

Table 4. Emergence of procedural codes, using example of "paying attention to translations"

\begin{tabular}{|c|c|c|c|}
\hline \multicolumn{4}{|c|}{ Procedural grouping of concepts } \\
\hline $1^{\text {st }}$ image & nd image & $3^{\text {rd }}$ image & Concept \\
\hline $\begin{array}{l}\text { Paid attention to } \\
\text { translations } \\
\text { expectation, } \\
\text { amount of retrieved results, } \\
\text { language hint, } \\
\text { search translations } \\
\text { Interacted with translations } \\
\text { Clicked on translations } \\
\text { expectation, } \\
\text { experiment } \\
\text { Retyped the translations } \\
\text { failure to understand } \\
\text { system's functionality, } \\
\text { image's language learned, } \\
\text { normal search behaviour, } \\
\text { impulse (not knowing why) } \\
\text { Did not interact with } \\
\text { translations } \\
\text { failure to understand } \\
\text { system's functionality } \\
\text { Did not pay attention to } \\
\text { translations } \\
\text { amount of attention, } \\
\text { understanding of the task, } \\
\text { focused on searching, } \\
\text { expectation }\end{array}$ & $\begin{array}{l}\text { Paid attention to } \\
\text { translations } \\
\text { expectation, } \\
\text { amount of retrieved results, } \\
\text { language hint, } \\
\text { search translations, } \\
\text { confusing results, } \\
\text { system's functionality, } \\
\text { learn the language of a } \\
\text { wording, } \\
\text { check search terms } \\
\text { Interacted with translations } \\
\text { Clicked on translations } \\
\text { expectation, } \\
\text { experiment, } \\
\text { failure to understand } \\
\text { system's functionality } \\
\text { Retyped the translations } \\
\text { failure to understand } \\
\text { system's functionality, } \\
\text { image's language learned, } \\
\text { normal search behaviour, } \\
\text { impulse (not knowing why), } \\
\text { system's failure to } \\
\text { automatically search the } \\
\text { translation, } \\
\text { users' interpretation of } \\
\text { system's functionality } \\
\text { Did not interact with }\end{array}$ & $\begin{array}{l}\text { Paid attention to } \\
\text { translations } \\
\text { expectation, } \\
\text { amount of retrieved results, } \\
\text { language hint, } \\
\text { search translations, } \\
\text { confusing results, } \\
\text { systems' functionality, } \\
\text { learn the language of a } \\
\text { wording, } \\
\text { check search terms, } \\
\text { language skills } \\
\text { Interacted with translations } \\
\text { Clicked on translations } \\
\text { expectation, } \\
\text { experiment, } \\
\text { failure to understand } \\
\text { system's functionality } \\
\text { Retyped the translations } \\
\text { failure to understand } \\
\text { system's functionality, } \\
\text { image's language learned, } \\
\text { normal search behaviour, } \\
\text { impulse (not knowing why), } \\
\text { system's failure to } \\
\text { automatically search the } \\
\text { translation, } \\
\text { users' interpretation of } \\
\text { system's functionality }\end{array}$ & $\begin{array}{l}\text { Paid attention to translations } \\
\text { expectation, } \\
\text { amount of retrieved results, } \\
\text { language hint, } \\
\text { search translations, } \\
\text { confusing results, } \\
\text { system's functionality, } \\
\text { learn the language of a } \\
\text { wording, } \\
\text { check search terms, } \\
\text { language skills } \\
\text { Interacted with translations } \\
\text { Clicked on translations } \\
\text { expectation, experiment, } \\
\text { failure to understand system's } \\
\text { functionality } \\
\text { Retyped the translations } \\
\text { failure to understand system's } \\
\text { functionality, } \\
\text { image's language learned, } \\
\text { normal search behaviour, } \\
\text { impulse (not knowing why), } \\
\text { system's failure to } \\
\text { automatically search the } \\
\text { translation, } \\
\text { users' interpretation of } \\
\text { system's functionality } \\
\text { Did not interact with } \\
\text { translations }\end{array}$ \\
\hline
\end{tabular}




\begin{tabular}{|l|l|l|l|}
\hline & $\begin{array}{l}\text { translations } \\
\text { failure to understand } \\
\text { system's functionality }\end{array}$ & $\begin{array}{l}\text { Did not interact with } \\
\text { translations } \\
\text { failure to understand } \\
\text { system's functionality, } \\
\text { users' reliance on system, } \\
\text { trust that system brought the } \\
\text { right results } \\
\text { translations } \\
\text { amount of attention, } \\
\text { understanding of the task, } \\
\text { focused on searching, } \\
\text { expectation, } \\
\text { trust in FlickLing }\end{array}$ & $\begin{array}{l}\text { Did not pay attention to } \\
\text { translations } \\
\text { amount of attention, } \\
\text { understanding of the task, } \\
\text { functionality, } \\
\text { users' reliance on system, } \\
\text { trust that system brought the } \\
\text { right results } \\
\text { trust in FlickLing }\end{array}$
\end{tabular}$\quad$\begin{tabular}{l}
$\begin{array}{l}\text { Did not pay attention to } \\
\text { translations } \\
\text { amount of attention, } \\
\text { understanding of the task, } \\
\text { focused on searching, } \\
\text { expectation, } \\
\text { trust in FlickLing }\end{array}$ \\
\hline
\end{tabular}

\subsection{Axial coding}

Although open and axial coding differ in purpose, they are not necessarily sequential steps (Strauss \& Corbin, 1998). Axial coding does require some concepts but the way that each concept relates to another is often apparent even during open coding. Axial coding attempts to answer questions such as 'how' and 'why', which lets relationships emerge. In coding in process, axial coding aims to relate actions and interactions over time as a response to a problem or issue with conditions and consequences.

In this study, the process was identified in the diagrams created from the recordings (Table 5.). These diagrams represented users' actions and interactions while searching for the three images.

Table 5. Process identification example

\begin{tabular}{|l|l|}
\hline \multicolumn{1}{|c|}{ Process } & \multicolumn{1}{c|}{ User G1/01 } \\
\hline [System feature $]$ & $1^{\text {st }}$ image \\
\hline [System feature $]$ & monolingual mode \\
\hline & $\ldots$ \\
\hline Action or interaction & {$[$ typed] windmill Holland } \\
\hline Action or interaction & {$[$ clicked] search } \\
\hline Consequence & 500 retrieved results \\
\hline Action or interaction & scrolled down \\
\hline & $\ldots$ \\
\hline
\end{tabular}

Once the process (searching for images across languages) and its components (actions, interactions, and consequences) were identified, they had to be integrated with structure, that is the problems, events, and happenings related to a phenomenon and consisting of conditions. Conditions thus relate the "why" questions of the actions and interactions and link to the phenomenon studied in an explanatory way. The transcripts from the retrospective thinking aloud were analysed to discover the conditions explaining users' actions and interactions and consequences. In particular, users' explanations of every action and interaction for all three images were identified as conditions and placed in each user's diagram after each relevant action and interaction and consequence. Each users' actions and interactions were compared with their expressions and thought processes for all 
three images. In this way, integration of structure and process was achieved (Table 6.).

Table 6. Structure \& process integration example

\begin{tabular}{|l|l|}
\hline \multicolumn{1}{|c|}{ Structure \& process } & \multicolumn{1}{c|}{ User G1/01 } \\
\hline [System feature] & $1^{\text {st } \text { image }}$ \\
\hline [System feature] & monolingual mode \\
\hline & $\ldots$ \\
\hline Action or interaction & [typed] windmill Holland \\
\hline Condition & $\begin{array}{l}\text { "there was a search hint and then I thought, I will } \\
\text { just linked Holland with windmills and thinking } \\
\text { maybe that was the image" }\end{array}$ \\
\hline Action or interaction & {$[$ clicked] search } \\
\hline Consequence & 500 retrieved results \\
\hline Condition & $\begin{array}{l}\text { “there were lots of them and I was just trying to } \\
\text { find, trying to be more specific, thinking” }\end{array}$ \\
\hline Action or interaction & scrolled down \\
\hline & ... \\
\hline
\end{tabular}

The combination of structure with process enables the researcher to understand some of the complexity that is part of real life and also to discern the emergence of the phenomenon. According to Strauss and Corbin (1998), only when the combination of structure and process is studied can the researcher capture the dynamic and evolving nature of events and build theory.

Once users' actions and interactions were related to their thoughts (conditions), a further comparison was applied with a view to identifying possible similarities and differences in users' expressions. These expressions were further compared with the expressions of those users who on the same interface/mode acted differently (e.g. those who started on monolingual compared with those who started their search on multilingual mode) to provide a further insight on users' thoughts processes. This process of constant comparison enabled the identification of instances where the same thought (code) resulted in different actions, or different thoughts (codes) resulted in the same action (Table 7.). 
Table 7. Constant comparison of users' actions and thoughts using the concept of modes usage as example

\begin{tabular}{|c|c|c|}
\hline \multicolumn{3}{|l|}{ Search for three images } \\
\hline $1^{\text {st }}$ image & image & image \\
\hline $\begin{array}{l}\text { Action: } \\
\text { Only monolingual mode ( } 9 \text { users }[01 \text {, } \\
04,07,09,10,12,13,19,24]) \\
\text { Condition: } \\
\text { Concept: Modes usage } \\
\text { Codes: } \\
\text { - the amount of attention users paid } \\
\text { on the modes; } \\
\text { - the way they interpreted modes } \\
\text { functionality; } \\
\text { the amount of confidence they } \\
\text { had in their language skills }\end{array}$ & $\begin{array}{l}\text { Action: } \\
\text { Only monolingual mode ( } 3 \text { users [01, } \\
\text { 13, 19]) } \\
\text { Condition: } \\
\text { Concept: Modes usage } \\
\text { Codes: } \\
\text { - the amount of attention users paid } \\
\text { on the modes; } \\
\text { the way they interpreted modes } \\
\text { functionality; } \\
\text { the amount of confidence they } \\
\text { had in their language skills. }\end{array}$ & $\begin{array}{l}\text { Action: } \\
\text { Only monolingual mode ( } 3 \text { users }[01, \\
\text { 13, 19]) } \\
\text { Condition: } \\
\text { Concept: Modes usage } \\
\text { Codes: } \\
\text { - the amount of attention users paid } \\
\text { on the modes; } \\
\text { the way they interpreted modes } \\
\text { functionality; } \\
\text { the amount of confidence they } \\
\text { had in their language skills }\end{array}$ \\
\hline $\begin{array}{l}\text { Action: } \\
\text { Only multilingual mode ( } 2 \text { users [06, } \\
\text { 16]) } \\
\text { Condition: } \\
\text { Concept: Modes usage } \\
\text { Codes: } \\
\text { - the amount of attention users paid } \\
\text { on the modes; } \\
\text { the way they interpreted modes } \\
\text { functionality; } \\
\text { the amount of confidence they } \\
\text { had in their language skills }\end{array}$ & $\begin{array}{l}\text { Action: } \\
\text { Only multilingual mode ( } 3 \text { users [02, } \\
06,17] \text { ) } \\
\text { Condition: } \\
\text { Concept: Modes usage } \\
\text { Codes: } \\
\text { - the amount of attention users paid } \\
\text { on the modes; } \\
\text { the way they interpreted modes } \\
\text { functionality; } \\
\text { the amount of confidence they } \\
\text { had in their language skills }\end{array}$ & $\begin{array}{l}\text { Action: } \\
\text { Only multilingual mode (1 user [06]) } \\
\text { Condition: } \\
\text { Concept: Modes usage } \\
\text { Codes: } \\
\text { - the amount of attention users paid } \\
\text { on the modes; } \\
\text { the way they interpreted modes } \\
\text { functionality; } \\
\text { the amount of confidence they } \\
\text { had in their language skills }\end{array}$ \\
\hline $\begin{array}{l}\text { Action: } \\
\text { Switching between the two }(9 \text { users } \\
[02,05,11,14,15,17,20,21,23]) \\
\text { Condition: } \\
\text { Concept: Modes usage } \\
\text { Codes: } \\
\text { - the amount of attention users paid } \\
\text { - } \quad \text { the way users interpreted modes; } \\
\text { - overall systems functionality; } \\
\text { - users' normal search behaviour; } \\
\text { - users' trust in applications; } \\
\text { - users' previous experience in } \\
\text { - } \quad \text { the warching; }\end{array}$ & $\begin{array}{l}\text { Action: } \\
\text { Switching between the two }(14 \text { users } \\
{[04,05,07,09,10,11,12,14,15,16,} \\
\text { 20,21,23, 24]) } \\
\text { Condition: } \\
\text { Concept: Modes usage } \\
\text { Codes: } \\
\text { - the way users interpreted modes; } \\
\text { - overall systems functionality; } \\
\text { - users' normal behaviour; } \\
\text { - users' previous experience in } \\
\text { - } \quad \text { foarching; }\end{array}$ & $\begin{array}{l}\text { Action: } \\
\text { Switching between the two (16 users } \\
{[02,04,05,07,09,10,11,12,14,15,} \\
\text { 16, 17,20,21,23, 24]) } \\
\text { Condition: } \\
\text { Concept: Modes usage } \\
\text { Codes: } \\
\text { - the way users interpreted modes; } \\
\text { - } \quad \text { overall systems functionality; } \\
\text { - users' normal search behaviour; } \\
\text { - users' trust in applications; } \\
\text { - } \quad \text { foreign context; } \\
\text { - } \quad \text { users' expectations of the system }\end{array}$ \\
\hline $\begin{array}{l}\text { Action: } \\
\text { Residual cases ( } 4 \text { users }[22,03,08, \\
18] \text { ) }\end{array}$ & $\begin{array}{l}\text { Action: } \\
\text { Residual cases ( } 4 \text { users }[22,03,08, \\
18])\end{array}$ & $\begin{array}{l}\text { Action: } \\
\text { Residual cases (4 users [22, 03, 08, } \\
18] \text { ) }\end{array}$ \\
\hline $\begin{array}{l}\text { Condition: } \\
\text { Concept: Modes usage } \\
\text { Codes: } \\
\text { - users' normal search behaviour; }\end{array}$ & $\begin{array}{l}\text { Condition: } \\
\text { Concept: Modes usage } \\
\text { Codes: } \\
\text { - users' normal search behaviour; }\end{array}$ & $\begin{array}{l}\text { Condition: } \\
\text { Concept: Modes usage } \\
\text { Codes: } \\
\text { - the way users interpreted modes; }\end{array}$ \\
\hline
\end{tabular}


Library and Information Science Research, 37(1),2015 pp77-87

\begin{tabular}{|l|l|l|}
\hline \multicolumn{2}{|l|}{ Search for three images } \\
\hline $\mathbf{1}^{\text {st }}$ image & $\mathbf{2}^{\text {nd }}$ image & $\mathbf{3}^{\text {rd }}$ image \\
\hline$\bullet \quad$ the way users interpreted modes & $\bullet \quad \begin{array}{l}\text { foreign context; } \\
\text { the way users interpreted modes }\end{array}$ & $\bullet \quad$ foreign context \\
\hline
\end{tabular}

\subsection{Selective coding}

The final step of coding in process is selective coding (Strauss \& Corbin, 1998). During selective coding the data broken down and compared during open and axial coding are reassembled and refined and again compared to build the emergent theory. The study's focus on coding was procedural, with a view to trying to understand how decisions were made by the 24 users when searching for images across languages. Analysis considered the type of data used and the way in which they were integrated and analysed (Table 8). 
Table 8. Linking data collection procedure with concepts

\begin{tabular}{|c|c|c|c|c|}
\hline \multicolumn{5}{|c|}{ Data collection } \\
\hline $1^{\text {st }}$ phase & \multicolumn{3}{|c|}{$2^{\text {nd }}$ phase } & $3^{\text {rd }}$ phase \\
\hline Before engaging with the & \multicolumn{3}{|c|}{ Searching the three images } & After engaging with the task \\
\hline & $1^{\text {st }}$ image & $2^{\text {nd }}$ image & $3^{\text {rd }}$ image & \\
\hline $\begin{array}{l}1^{\text {st }} \text { questionnaire } \\
2^{\text {nd }} \text { questionnaire } \\
\text { Interviews } \\
\text { RTA }\end{array}$ & Videos, RTA & Videos, RTA & Videos, RTA & $\begin{array}{l}2^{\text {nd }} \& 3^{\text {rd }} \text { questionnaire } \\
\text { Interviews }\end{array}$ \\
\hline \multicolumn{5}{|c|}{ Concepts } \\
\hline $\begin{array}{l}\text { users' trust, users' } \\
\text { confidence, } \\
\text { thinking about } \\
\text { languages, language } \\
\text { skills (personal } \\
\text { knowledge of } \\
\text { languages) }\end{array}$ & 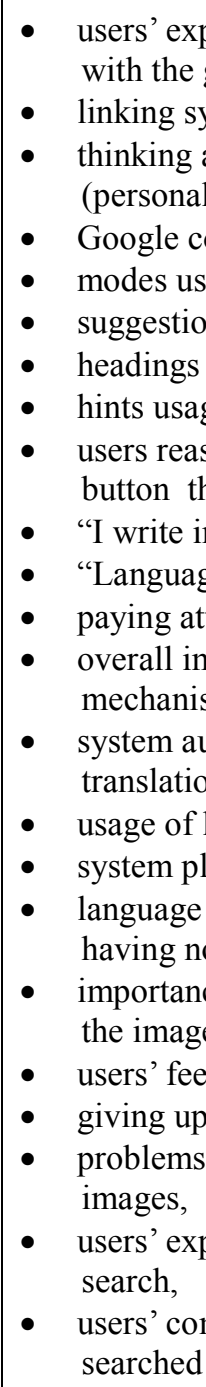 & $\begin{array}{l}\text { ssions when fi } \\
\text { en images, } \\
\text { em, } \\
\text { ut languages, } \\
\text { owledge of la } \\
\text { ments, } \\
\text { usage, } \\
\text { d tags usage, } \\
\text { s for clicking } \\
\text { first time, } \\
\text { anguage" featu } \\
\text { outtons" featur } \\
\text { tion to translat } \\
\text { ession of the t } \\
\text { matically retric } \\
\text { guage as a sea } \\
\text { ing around, } \\
\text { ills (as a conse } \\
\text { nowledge of la } \\
\text { of knowing th } \\
\text { gs, } \\
\text { countered bef } \\
\text { ssed reasons fo } \\
\text { nents regarding } \\
\text { FlickLing }\end{array}$ & $\begin{array}{l}\text { t confronted } \\
\text { anguage skills } \\
\text { guages), } \\
\text { e "give up" } \\
\text { e usage, } \\
\text { usage, } \\
\text { ons, } \\
\text { anslation } \\
\text { ing } \\
\text { uence of } \\
\text { guages), } \\
\text { language of } \\
\text { ceasing a } \\
\text { the way they }\end{array}$ & $\begin{array}{l}\text { - language skills (as a } \\
\text { consequence of having no } \\
\text { knowledge of languages), } \\
\text { - } \text { importance of knowing the } \\
\text { language of the image, } \\
\text { - users' feelings, } \\
\text { - } \text { giving up, } \\
\text { problems encountered before } \\
\text { - } \text { finding the images, } \\
\text { - users' trust, } \\
\text { - users' confidence, } \\
\text { - users' expressed reasons for } \\
\text { - users' comments regarding the } \\
\text { way they searched in FlickLing }\end{array}$ \\
\hline
\end{tabular}

The concepts and codes which emerged from the open and axial coding were divided into three distinct areas: preconditions, actions and consequences. These areas again emerged after a constant comparison of the concepts and their codes and sub-codes and of users' actions and interactions. Comparative analysis revealed that these referred to users' actions before the task, during and after the completion of the search. Each phase represented a separate part of users' searching experiences. In particular, concepts concerning users' comments before interacting with FlickLing were defined as preconditions, concepts referring to users' actions while searching in FlickLing as 
actions, and concepts regarding users' search outcomes and comments after the completion of the task as consequences (Table 9). This was done to ensure the integration of structure with process at a more abstract level and the reflection of the process in the generated substantive theory.

Table 9. Procedural assignment of concepts

\begin{tabular}{|c|c|c|}
\hline & & Process integrated in substantive theory \\
\hline & ding in process & Concepts \\
\hline 1 & preconditions & $\begin{array}{l}\text { - } \quad \text { users' trust, users' confidence, } \\
\text { - } \quad \text { linking system, } \\
\text { - } \quad \text { thinking about languages, } \\
\text { - language skills (personal knowledge of languages), } \\
\text { - Google comments }\end{array}$ \\
\hline 2 & actions & $\begin{array}{l}\text { - } \quad \text { modes' usage, } \\
\text { - } \quad \text { heaggestions usage, } \\
\text { - } \text { hints usage, } \\
\text { - } \quad \text { users reasons for clicking the "give up" button the first time, } \\
\text { - } \quad \text { "Language buttons" feature usage, } \\
\text { - } \quad \text { paying attention to translations, } \\
\text { - } \quad \text { overall impression of the translation mechanism, } \\
\text { - } \quad \text { usage of language as a search term, } \\
\text { - } \quad \text { system playing around }\end{array}$ \\
\hline 3 & consequences & $\begin{array}{l}\text { - language skills (as a consequence of having no knowledge of languages), } \\
\text { - } \quad \text { importance of knowing the language of the image, } \\
\text { - } \text { giving up, } \\
\text { - } \text { problems encountered before finding the images, } \\
\text { - users' trust, } \\
\text { - users' confidence, } \\
\text { - users' expressed reasons for ceasing a search, } \\
\text { users' comments regarding the way they searched in FlickLing }\end{array}$ \\
\hline
\end{tabular}

When assigned in this way, as procedure with preconditions, actions and consequences, four conceptual categories emerged after a constant comparison of the concepts, their codes, and subcodes. The categories were knowledge of languages, query domain, system, and search. When the concept and codes, grouped by the procedural areas (precondition, action and consequence), were assigned to these categories, each of the four conceptual categories were identified as factors related and interrelated to the users' searching experience in the multilingual environment (Table 10). 
Table 10. Procedural assignment of concepts to four factors

\begin{tabular}{|c|c|c|c|c|}
\hline \multicolumn{5}{|c|}{ Conceptual categories/ factors } \\
\hline Coding in process & $\begin{array}{l}\text { Knowledge of } \\
\text { languages }\end{array}$ & Query domain & Search & System \\
\hline Preconditions & 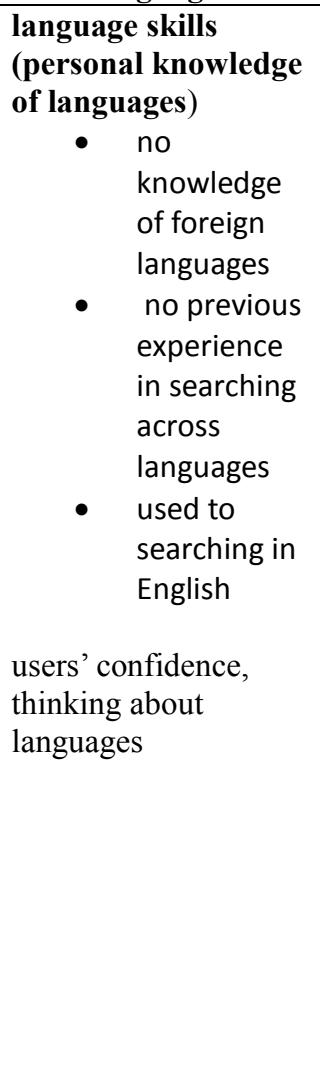 & $\begin{array}{l}\text { users' expressions } \\
\text { when first } \\
\text { confronted with the } \\
\text { images } \\
\text { - } \quad \text { find search } \\
\text { - } \quad \text { interms } \\
\text { image } \\
\text { - } \quad \text { identify the } \\
\text { language of } \\
\text { the image } \\
\text { normal } \\
\text { search } \\
\text { behaviour } \\
\text { find } \\
\text { translations } \\
\text { previous } \\
\text { experience } \\
\text { in searching } \\
\text { for images } \\
\text { users' trust, users' } \\
\text { confidence }\end{array}$ & $\begin{array}{ll}\text { linking system } \\
\text { - } & \text { linking } \\
& \text { search } \\
& \text { terms with } \\
& \text { the country } \\
\text { - } & \text { linking } \\
& \text { language } \\
& \text { and country } \\
\text { - } & \text { systems } \\
& \text { failure to } \\
& \text { link terms } \\
\text { - } & \text { linking } \\
& \text { users' } \\
& \text { knowledge } \\
& \text { of language } \\
& \text { with } \\
& \text { systems } \\
& \text { results } \\
\text { - } & \text { link images } \\
& \text { and } \\
\text { languages } & \text { link search } \\
\text { terms with } & \text { images } \\
\text { users' trust, users' } \\
\text { confidence }\end{array}$ & $\begin{array}{ll}\text { Google comments } \\
\text { - } & \text { searched the } \\
& \text { same way as } \\
& \text { in Google } \\
\text { - } & \text { prefer printed } \\
\text { books over } & \text { Google } \\
\text { - } & \text { would prefer } \\
& \text { to go on } \\
& \text { Google and } \\
& \text { take } \\
\text { translations } & \text { expectation } \\
\text { - } \quad \text { users' } \\
\text { reliance } \\
\text { trusted } \\
\text { FlickLing over } \\
\text { Google } \\
\text { more } \\
\text { academic } \\
\text { Google, } \\
\text { everyone puts } \\
\text { everything } \\
\text { there } \\
\text { users' trust, }\end{array}$ \\
\hline Actions & $\begin{array}{l}\text { modes usage, } \\
\text { suggestions usage, } \\
\text { headings and tags } \\
\text { usage, hints usage, } \\
\text { users reasons for } \\
\text { clicking the given up } \\
\text { button on the first } \\
\text { place, "I write in } \\
\text { language" feature } \\
\text { usage, "language } \\
\text { buttons" feature } \\
\text { usage, } \\
\text { paying attention to } \\
\text { translations } \\
\text { - learn the } \\
\quad \text { language of } \\
\text { the wording } \\
\text { - language hint } \\
\text { • language skills } \\
\text { - search } \\
\text { translations } \\
\text { overall impression of } \\
\text { the translation } \\
\text { mechanism, system } \\
\text { automatically } \\
\text { retrieving translations, }\end{array}$ & $\begin{array}{l}\text { suggestions usage, } \\
\text { headings and tags } \\
\text { usage, hints usage, } \\
\text { users reasons for } \\
\text { clicking the given up } \\
\text { button the first time, } \\
\text { paying attention to } \\
\text { translations } \\
\text { • amount of } \\
\text { retrieved } \\
\text { results } \\
\text { - confusing } \\
\text { results } \\
\text { - check search } \\
\text { terms } \\
\text { - understanding } \\
\text { of the task } \\
\text { - amount of } \\
\text { attention } \\
\text { paid } \\
\text { overall impression of } \\
\text { the translation } \\
\text { mechanism, system } \\
\text { automatically } \\
\text { retrieving } \\
\text { translations, usage of }\end{array}$ & $\begin{array}{l}\text { modes usage, } \\
\text { suggestions usage, } \\
\text { headings and tags } \\
\text { usage, hints usage, } \\
\text { users reasons for } \\
\text { clicking the given up } \\
\text { button the first time, } \\
\text { "I write in language" } \\
\text { feature usage, } \\
\text { "language buttons" } \\
\text { feature usage, } \\
\text { paying attention to } \\
\text { translations } \\
\text { - expectation } \\
\text { - amount of } \\
\text { retrieved } \\
\text { results } \\
\text { - search } \\
\text { translations } \\
\text { - experiment } \\
\text { - expectation } \\
\text { - normal search } \\
\text { behaviour } \\
\text { - impulse } \\
\text { - focused on } \\
\text { search }\end{array}$ & $\begin{array}{l}\text { modes usage, } \\
\text { suggestions usage, } \\
\text { headings and tags } \\
\text { usage, hints usage, } \\
\text { users reasons for } \\
\text { clicking the given up } \\
\text { button the first time, "I } \\
\text { write in language" } \\
\text { feature usage, } \\
\text { "language buttons" } \\
\text { feature usage, } \\
\text { paying attention to } \\
\text { translations } \\
\text { - system's } \\
\text { functionality } \\
\text { - experiment } \\
\text { - failure to } \\
\text { understand } \\
\text { system's } \\
\text { functionality } \\
\text { - users' } \\
\text { interpretation } \\
\text { of system's } \\
\text { functionality } \\
\text { - users' reliance } \\
\text { on system } \\
\text { trust that }\end{array}$ \\
\hline
\end{tabular}




\begin{tabular}{|c|c|c|c|c|}
\hline \multicolumn{5}{|c|}{ Conceptual categories/ factors } \\
\hline Coding in process & $\begin{array}{c}\text { Knowledge of } \\
\text { languages }\end{array}$ & Query domain & Search & System \\
\hline & $\begin{array}{l}\text { usage of language as a } \\
\text { search term }\end{array}$ & $\begin{array}{l}\text { language as a search } \\
\text { term }\end{array}$ & $\begin{array}{l}\text { overall impression of } \\
\text { the translation } \\
\text { mechanism, system } \\
\text { automatically } \\
\text { retrieving } \\
\text { translations, usage of } \\
\text { language as a search } \\
\text { term }\end{array}$ & $\begin{array}{l}\text { system } \\
\text { brought the } \\
\text { right results }\end{array}$ \\
\hline Consequences & $\begin{array}{l}\text { language skills (as a } \\
\text { consequence of } \\
\text { having no knowledge } \\
\text { of languages) } \\
\text { - } \quad \text { stop } \\
\text { searching } \\
\text { not able to } \\
\text { understand } \\
\text { - } \text { search for } \\
\text { translations } \\
\text { trust in } \\
\text { system } \\
\text { no trust in } \\
\text { languages } \\
\text { skills } \\
\text { difficult } \\
\text { searching } \\
\text { across } \\
\text { languages } \\
\text { inability to } \\
\text { provide } \\
\text { translations } \\
\text { of search } \\
\text { terms } \\
\text { need to have } \\
\text { knowledge } \\
\text { of language } \\
\text { to search in } \\
\text { confidence, users' } \\
\text { feelings }\end{array}$ & 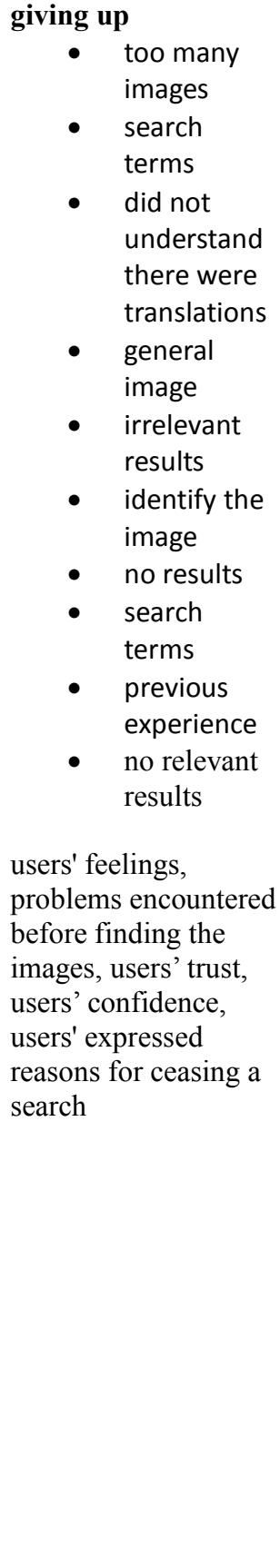 & 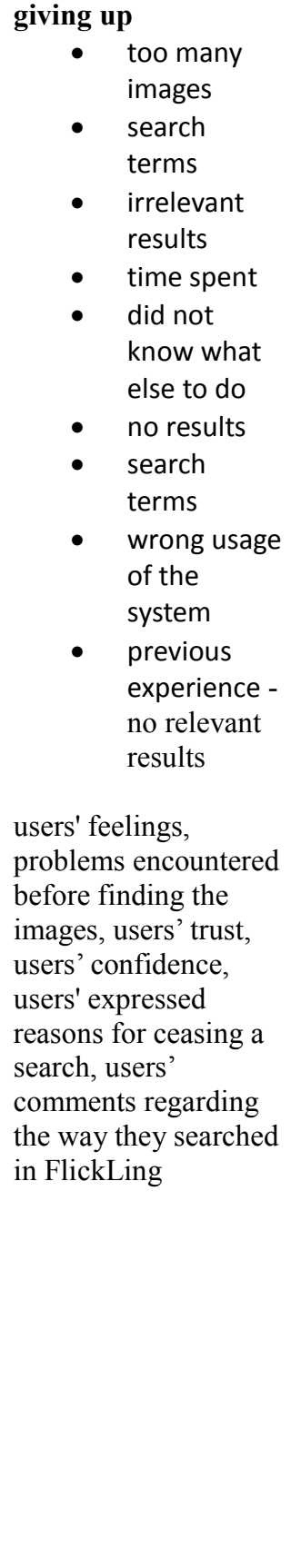 & 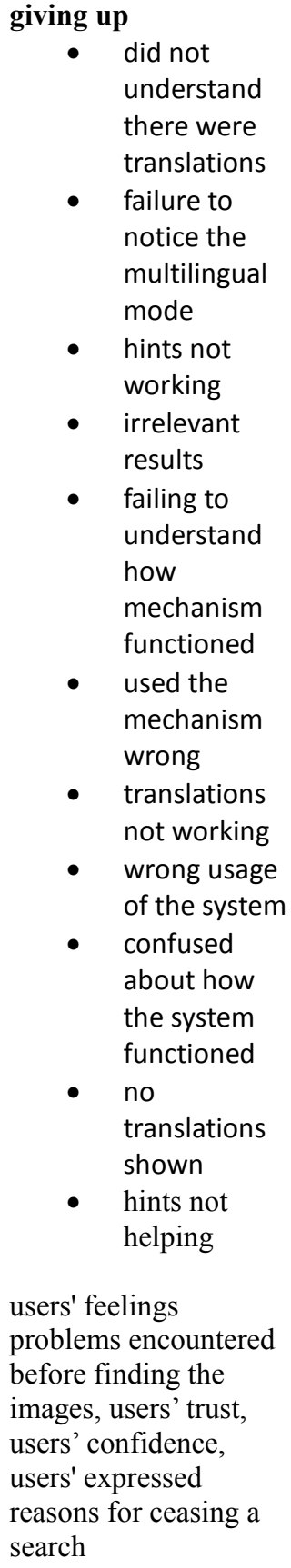 \\
\hline
\end{tabular}

\subsection{Substantive theory generation}


In grounded theory practice, once this process was completed for all concepts, it can be said that the elements of each conceptual category and the relationships among the concepts, codes, and subcodes have emerged. The final step was to illustrate the theory found in the data and its use to suggest the further modelling of search behaviour according to any one or combination of core categories at any point during a search (further elaborated in Vassilakaki, Johnson, \& Hartley ,2012) . To illustrate the theory diagrams, one for each conceptual category was then created and these formed the basis to demonstrate the variety and complexity of the users' behaviours that emerged through constant comparison. In particular, the diagrams highlighted the relationships found among concepts, codes, sub-code, and users' justifications assigned in each area (preconditions, actions, and consequences). The various links between the concepts in the diagrams demonstrated the complexity of search, and the relations found among the areas highlighted the flow of the concepts when grouped as the four prevalent factors in characterising search. Focusing here on the use of GT in describing and understanding search, the diagrams (Figures 1, 2, 3, and 4) show only the codes for the selected concept of paying attention to translations.'.

\section{KNOWLEDGE OF LANGUAGES DIAGRAM}

\section{PRECONDITIONS}

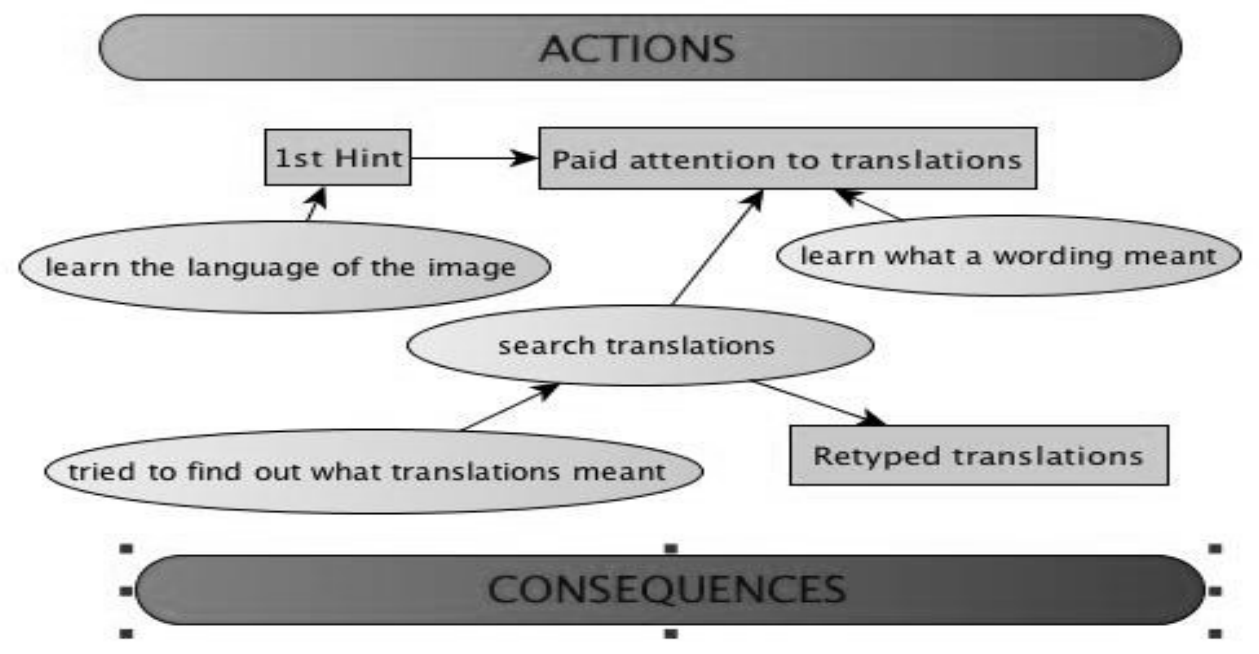

Figure 1. "Knowledge of languages" diagram 


\section{QUERY DOMAIN DIAGRAM}

\section{PRECONDITIONS}

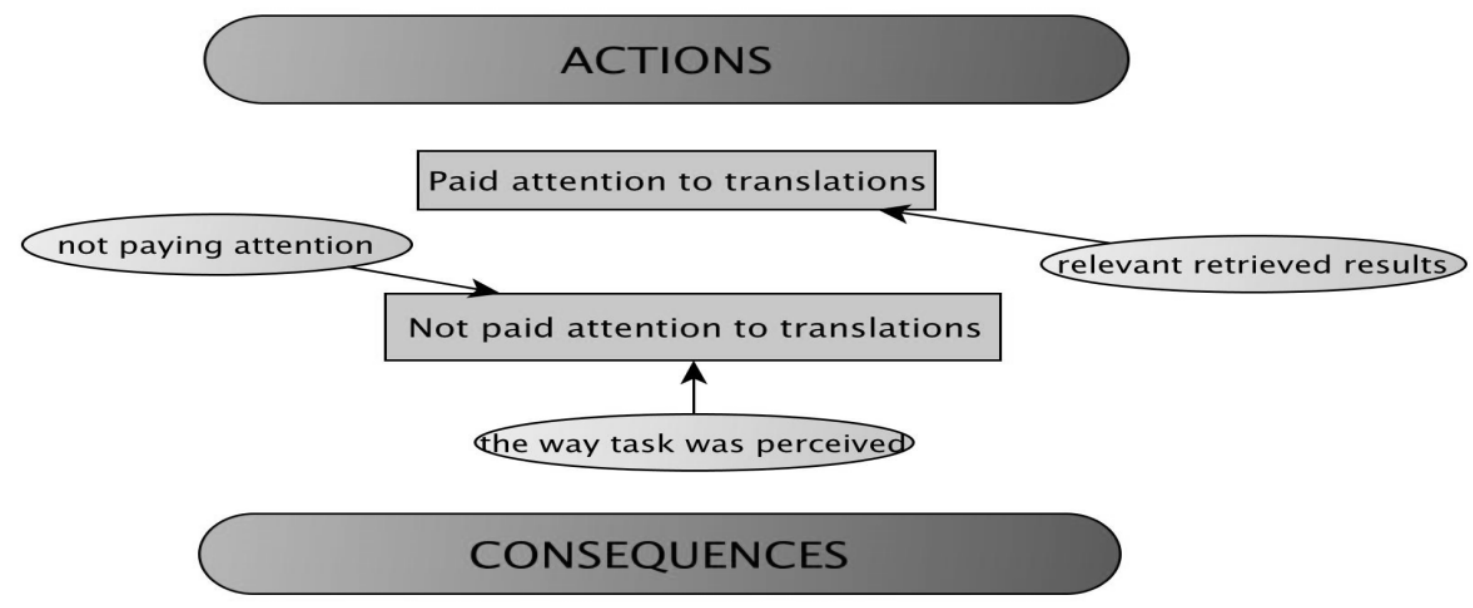

Figure 2 "Query domain” diagram

\section{SEARCH DIAGRAM}

\section{PRECONDITIONS}

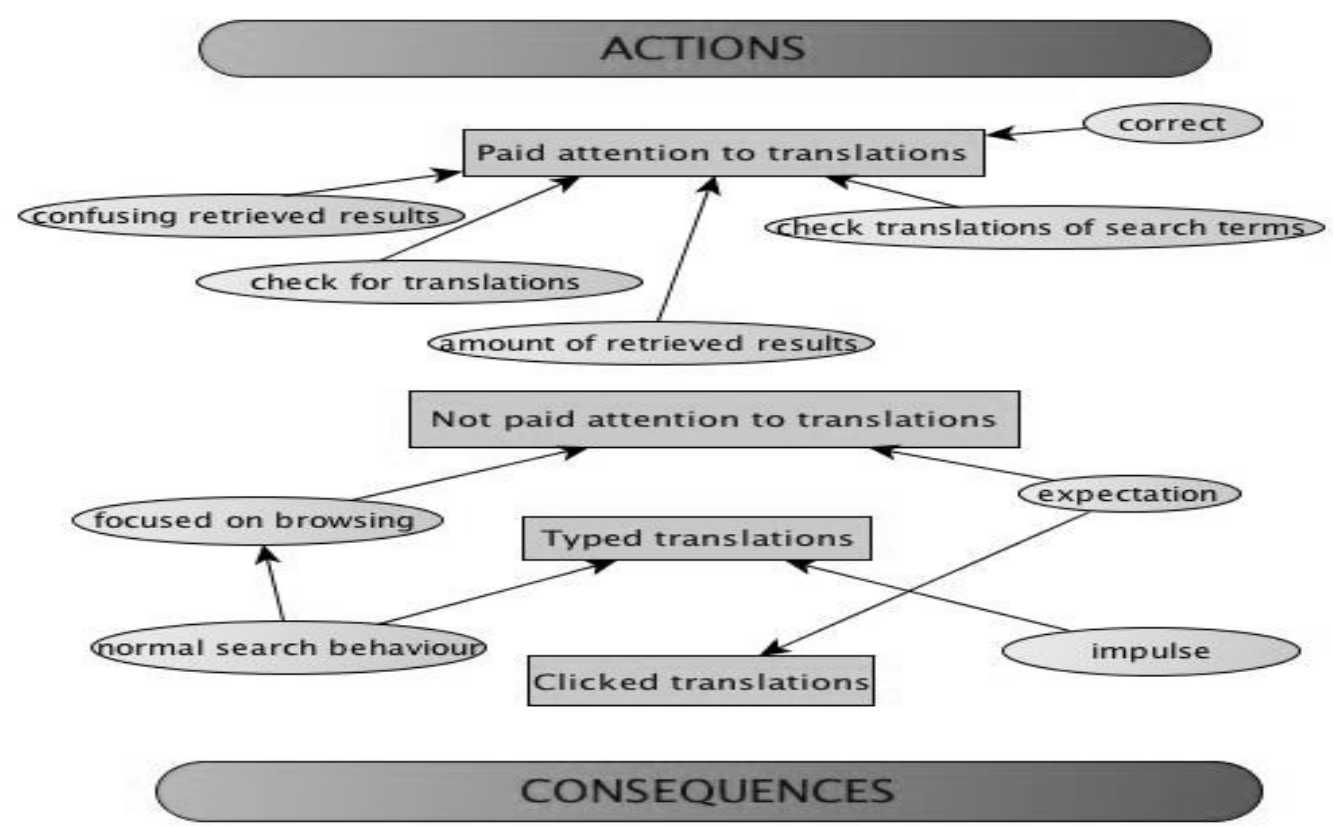

Figure 3. "Search" diagram 


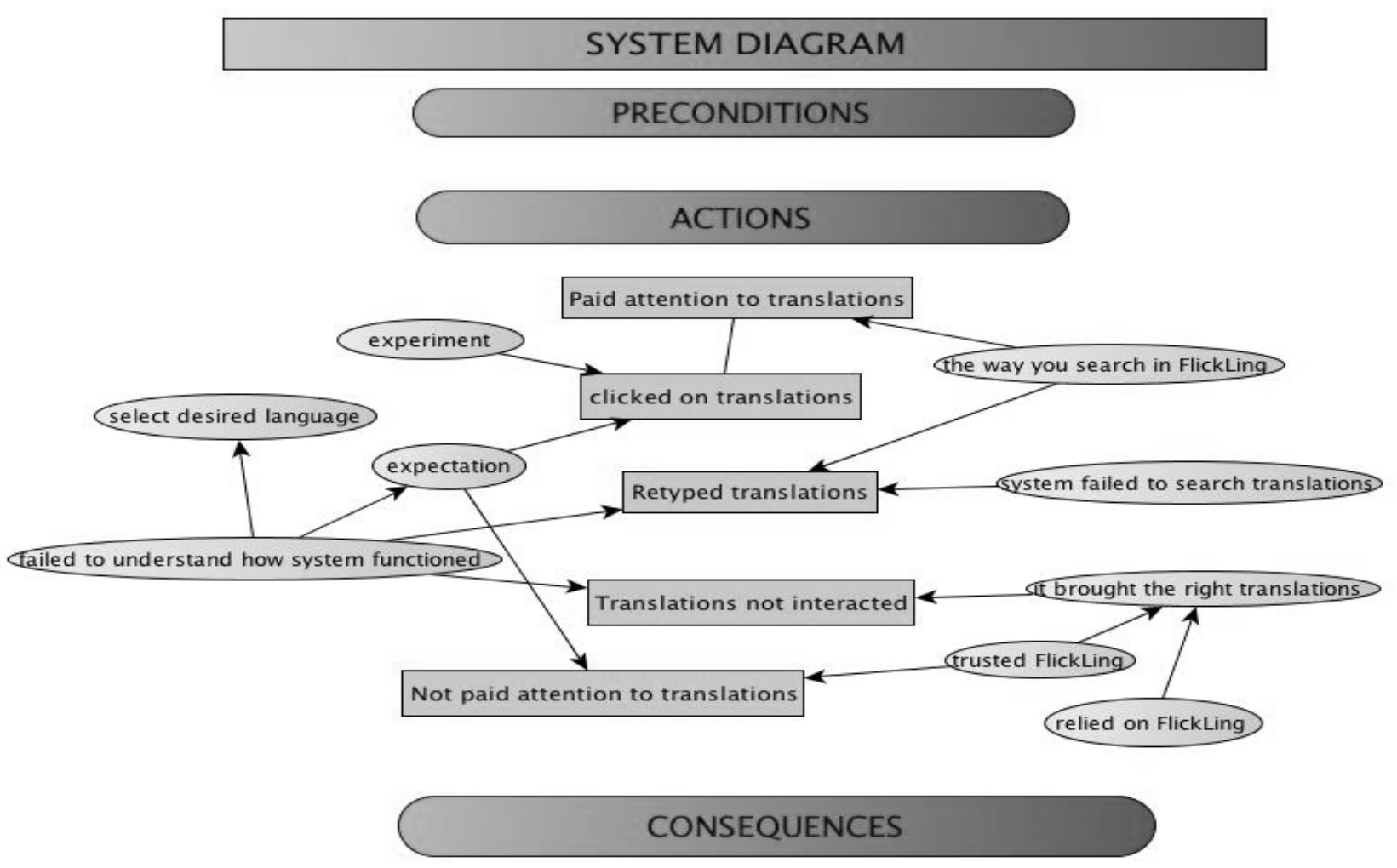

Figure 4. "System" diagram

\section{Discussion}

This study focused on exploring users' search behaviour from an entirely user perspective, contributing to the relevant research on MLIR. In particular, it identified users' actions and interactions with a MLIR system and shed light on users' own explanations of these actions. This was illustrated with the modelling of the one of the selected concepts - procedural analysis and the modelling of all of the identified concepts to present the substantive theory of users' information searching in multilingual environment is beyond the scope of this study. Nevertheless, the inductive approach of GT coupled with its procedural analysis to capture the relationships among concepts has enabled a description of the user experience in terms of the grouping of the main factors shown to be prevalent and interrelated across the users' thoughts and explanations when searching.

From the many models related to user interaction with retrieval systems, the present one relates most closely to those which assume the need to recognise a cognitive stage in the search process, such as thinking about the query, making relevance judgements, examining results, reflecting on whether the task has been solved, such as Bates' (1979) model which explored both the mental and the physical actions that comprise library system search. Bates proposed 29 search tactics and 17 idea tactics in an attempt to analyse exactly what happens during a search process. This allowed for a dynamic and flexible view of search with the mental actions explaining what was going on behind the physical actions. The present study differs in the context of searching for images in a multilingual system. Also, whereas Bates conceptualised the complexity of search with the range of search strategies and term tactics available, the present study focuses on the description of the user experience in terms of the grouping of the main prevalent and interrelated mental thoughts and explanations for actions during the process of search. Adopting the approach of grounded theory, this investigation has attempted to elicit the mental and cognitive actions that are part of the process of search and to illuminate those that are key and prevalent in affecting search behaviour. Thus in 
adopting the approach of grounded theory, this investigation has demonstrated the complexity of the user experience in which system evaluation is expected to take place.

One limitations is that a theoretical saturation was only achieved for the main conceptual categories of users' searching experiences in multilingual environments. Further research is needed to find whether more variations of the existing conceptual categories and of their subcategories exist. As a result, the revealed substantive theory can be only extended through identifying new codes and suc-codes of the existing categories and no more basic conceptual categories can be identified.

\section{Conclusion}

This study contributed to understanding of the context of user experience when searching across languages. The use of grounded theory enabled the investigation of users' thoughts and actions and the inductive approach coupled with the procedural analysis provided insight into users' information seeking behaviour. By coding the cognitive activities that take place in the physical process of an actual search, the complexity of the user experience was emphasized. The resulting model of search (depicted for just one of the observable actions in search) may remind the system developer of novel and innovative search interfaces that, at any point or identifiable action or interaction, the user is likely to be engaged in complex and challenging thought processess and that possible explanations for these actions relate to understanding the system, the query, the search and in the case of multilingual retrieval systems, the language and its translation. Perhaps the challenge for the system developer is determining how to support the dynamic process of information seeking behaviour without distracting users from their cognitive activities.

\section{References}

Bates, M. J. (1979). Information search tactics. Journal of the American Society for information Science, 30, 205-214.

Belkin, N. J. (1978). Information concepts for information science. Journal of Documentation, 34, 55-85.

Belkin, N. J., Oddy, R. N., \& Brooks, H. M. (1982). ASK for information retrieval: Part I. Background and theory. Journal of Documentation, 38, 61-71.

Borlund, P. (2003). The concept of relevance in IR. Journal of the American Society for information Science and Technology, 54, 913-925.

Bronstein, J. (2007). The role of the research phase in information seeking behaviour of Jewish studies scholars: A modification of Ellis's behavioural characteristics. Information Research, 12(3). Retrieved from http://informationr.net/ir/12-3/paper319.html

Chen, A., \& Gey, F. C. (2004). Multilingual information retrieval using machine translation, relevance feedback and decompounding. Information Retrieval, 7(1-2), 149-182.

Choo, C., \& Marton, C. (2003). Information seeking on the web by women in IT professions. Internet Research: Electronic Networking Applications and Policy, 13, 267-280.

Clough, P., Gonzalo, J., Karlgren, J., Barker, E., Artiles, J., \& Peinado, V. (2008). Large-scale interactive evaluation of multilingual information access systems: the iCLEF Flickr challenge. In Workshop on Novel Methodologies for Evaluation in Information Retrieval, 30 March 2008, Glasgow, Scotland, (pp. 33-38). Retrieved from http://ir.shef.ac.uk/cloughie/papers/ecirevaluation.pdf

Correia, Z., \& Wilson, T.D. (2001). Factors influencing environmental scanning in the organizational context. Information Research, 7(1), paper 121. Retrieved from http://informationr.net/ir/7-1/paper121.html

Cosijn, E., \& Ingwersen, P. (2000). Dimensions of relevance. Information Processing \& 
Management, 36, 533-550.

Ellis, D. (1989). A behavioral model to information retrieval system design. Journal of Information Science, 15:171-212.

Fidel, R., \& Soergel, D. (1983). Factors affecting online bibliographic retrieval: A conceptual framework for research. Journal of the American Society for Information Science, 34, 163-180.

Flick, U. (2004). Introducción a la investigación cualitativa [An introduction to qualitative research]. Madrid, Spain: Fundación Paideia Galiza.

Foster, A. (2004). A nonlinear model of information seeking behaviour. Journal of the American Society for Information Science and Technology, 55, 228-237.

Glaser, B.G., \& Strauss, A.L. (1967). The discovery of grounded theory: Strategies for qualitative research, Chicago, IL: Aldine.

González-Teruel, A., \& Abad-García, M. (2012). Grounded theory for generating theory in the study of behavior. Library \& Information Science, 34 (1), 31-36.

Ingwersen, P., \& Jarvelin, K. (2005). The turn: Integration of information seeking and retrieval in context. Dortrecht, Netherlands: Springer.

Ingwersen, P. \& Wormell, I. (1988). Means to improve subject access and representation in modern information retrieval. Libri, 38(2), 94-119.

Jarvelin, K. \& Ingwersen, P. (2012). User-oriented and cognitive models of information retrieval. In Bates, M.J (ed) Understanding Information Retrieval Systems: management, types and standards. US, New Work: Taylor \& Francis.

Jorna, K.. \& Davies, S. (2001). Multilingual thesauri for the modern world: No ideal solution. Journal of Documentation, 57, 284-295.

Kuhlthau, C. (1993). A principle of uncertainty for information seeking. Journal of Documentation, 49, 339-355.

Marchionini, G. (1995). Information-seeking in electronic environments: Cambridge Series on human computer interaction. Cambridge: Cambridge University Press.

Mackenzie P. (2003). A model of information practices in accounts of everyday-life information seeking. Journal of Documentation, 59, 19-40.

McKechnie, L., Baker, L., Greenwood, M., \& Julien, H. (2002). Research method trends in human information literature. New Review of Information Behaviour Research, 3, 113-125.

McKnight, M. (2007). A grounded theory model of on-duty critical care nurses' information behavior: The patient-chart cycle of informative interactions. Journal of Documentation, 63, 5773.

Musoke, M.G. (2007). Information behaviour of primary health care providers in rural Uganda: an interaction-value model. Journal of Documentation, 63, 299-322.

Pace, S. (2004). A grounded theory of the flow experiences of Web users. International Journal of Human Computer Studies, 60, 327--363.

Peinado, V., Lopez-Ostenero, F., \& Gonzalo, J. (2009). UNED at iCLEF 2009: analysis of multilingual image search sessions. In Cross Language Evaluation Forum 2009 Workshop Notes (p. 10). Retrieved from http://www.clef-campaign.org/2009/working_notes/peinadopaperCLEF2009.pdf.

Saracevic, T. (1996). Relevance considered. In P. Ingwersen, \& N. O. Pors (Eds.), Proceedings of the $2^{\text {nd }}$ International Conference on Conceptions of Library and Information Science, Copenhagen, Denmark, Oct 13-16 (pp. 201-218). Copenhagen, Denmark: Royal School of Librarianship.

Strauss, A.L., \& Corbin, J. (1998). Basics of qualitative research: Techniques and procedures for developing grounded theory, Thousand Oaks, CA: SAGE. 
Urquhart, C., Lehmann, H., \& Myers, M.D. (2010). Putting the "theory" back into grounded theory: Guidelines for grounded theory studies in information systems. Information Systems Journal, 20, 357-381.

Vakkari, P. (2001a). A theory of the task-based information retrieval process: A summary and generalisation of a longitudinal study. Journal of Documentation, 57, 44-60.

Vakkari, P. (2001b). Changes in search tactics and relevance judgements when preparing a research proposal: a summary of the findings of a longitudinal study. InformationRretrieval, 4, 295-310.

Vakkari, P. (2008). Trends and approaches in information behaviour research. Information Research, 13(4), paper 361. Retrieved from http://InformationR.net/ir/13-4/paper361.html.

Vassilakaki, E., Johnson, F., \& Hartley, R.J. (2012). Image seeking in multilingual environments: a study of the user experience. Information Research, 17(4), paper 359. Retrieved from http://InformationR.net/ir/17-4/paper539.html

Walker, D., \& Myrick, F. (2006). Grounded theory: an exploration of process and procedure. Qualitative Health Research, 16(4), 547-559.

Wang, P., \& Soergel, D. (1998). A cognitive model of document use during a research project. Study I. Document selection. Journal of the American Society for Information Science, 49, 115-133.

Wilson, T. (1997). Information behaviour: An interdisciplinary approach. Information Processing \& Management, 33, 551-572.

Wilson, T. (1999). Models in information behavior research. Journal of Documentation, 55, 249270.

Winkelman, W.J., Leonard, K.J., \& Rossos, P. G. (2005). Patient-perceived usefulness of online electronic medical records: employing grounded theory in the development of information and communication technologies for use by patients living with chronic illness. Journal of the American Medical Informatics Association, 12, 306-314.

Xie, B. (2009). Older adults' health information wants in the internet age: implications for patientprovider relationships. Journal of Health Communication, 14, 510-524.

\section{APPENDIX A.}

\section{2nd Questionnaire}

Please indicate your degree of trust and/or confidence in the following statements using the scale provided:

[Don’t know! Not at all A little So-so Very much so Totally]

1. In general, I trust applications on the web to help me do the things that I want to do.

2. In general, I trust the results that search engines on the web give me.

3. In general, I trust online translators to help me translate a text.

4. In general, for languages I do not understand, I trust provided translations for searching on the web.

5. In general, for languages of which I have some knowledge, I trust provided translations for searching on the web. 
6. In general, I trust for use the search terms suggested to me by search engines on the web.

7. In general, I trust Help instructions to understand the use of interfaces.

8. In general, I have confidence in my personal skills and abilities to search for images on the web.

9. In general, I have confidence in my language skills to search for images across languages on the web.

10. Note: If you possess no previous experience in searching on the web across languages, please skip this question In general, I have confidence when searching images across languages because of my relevant experience.

\section{3rd Questionnaire}

Please indicate your degree of trust and/or confidence in the following statements using the scale provided:

[Don't know! Not at all A little So-so Very much so Totally]

1. I trusted the results that FlickLing's monolingual mode gave me.

2. I trusted the results that FlickLing's multilingual mode gave me.

3. I trusted FlickLing to translate my query.

Note: In case you haven't used FlickLing's online translator, please go to question 6.

4. I trusted the translations FlickLing gives for languages I do not know.

5. I trusted the translations FlickLing gives for languages I understand.

6. I trusted FlickLing to suggest search terms.

7. I trusted the hints provided by FlickLing to search for the images

8. I trusted the help instructions to guide me through FlickLing.

9. I am confident that FlickLing helped me search across languages for the images.

10. I had confidence in my personal skills to search for the images in FlickLing.

11. I had confidence in my language skills to search for the images across languages in FlickLing.

12. I had confidence in the experience that I was gaining in FlickLing for searching the images across languages. 